\title{
Prevalence rates \\ and an evaluation of reported risk factors for osteonecrosis (avascular necrosis) in Crohn's disease
}

\author{
Hugh J Freeman MD, Katy J Freeman
}

HJ Freeman, KJ Freeman. Prevalence rates and an evaluation of reported risk factors for osteonecrosis (vascular necrosis) in Crohn's disease. Can J Gastroenterol 2000;14(2):138-143. Avascular necrosis (osteonecrosis) occurs in Crohn's disease, but the rate of this particular complication is not known. Over 20 years, 877 patients with Crohn's disease, 492 women (56.1\%) and 385 men $(43.9 \%)$, were evaluated with patient follow-up data available for a mean of 7.8 years. In this group, four men were seen with osteonecrosis. No woman was affected. All patients had typical radiological, magnetic resonance imaging or pathological changes of osteonecrosis involving the femoral heads, while two also had superimposed avascular necrosis involving the humeral heads. Patient ages ranged from 19 to 36 years at the time of diagnosis of their Crohn's disease, and all were white. In one patient, disease was confined to the colon, while three patients had disease involving the terminal ileum and colon. Disease behaviour in two patients was classified as penetrating because of concomitant ischiorectal abscesses, while one patient developed a metastatic colon carcinoma. Ankylosing spondylitis was present in two patients, but no other extraintestinal manifestations developed. Two patients received corticosteroids as well as parenteral nutrition during the course of their disease. Two patients did not receive corticosteroids or parenteral nutrition. Of 877 patients with Crohn's disease, $484(55.1 \%)$ received corticosteroids during the course of the disease, $196(22.4 \%)$ received at least one course of parenteral nutrition, and $125(14.3 \%)$ received both corticosteroids and parenteral nutrition. A total of 311 patients $(35.5 \%)$ had at least one small intestinal resection. The overall rate of avascular necrosis in Crohn's disease was less than $0.5 \%$ but for men with Crohn's disease was about $1 \%$. In this series, risk of osteonecrosis could not be attributed to corticosteroid use, parenteral nutrition or both forms of therapy administered together. Small intestinal resection with loss of small intestinal absorptive area was not a risk factor for the development of osteonecrosis. Avascular necrosis (or osteonecrosis) is a very rare extraintestinal osseous complication that may occur in Crohn's disease, independent of previously reported risk factors, including corticosteroids or parenteral nutrition with lipid emulsions.

Key Words: Avascular necrosis; Crohn's disease; Osteonecrosis

\section{Prévalence et évaluation des facteurs de risque d'ostéonécrose (nécrose avasculaire) dans la maladie de Crohn}

RÉSUMÉ : La nécrose avasculaire (ostéonécrose) accompagne la maladi de Crohn, mais le taux de prévalence de cette complication particulière est inconnu. Sur une période de 20 ans, 877 patients atteints de la maladie de Crohn, 492 femmes (56,1\%) et 385 hommes (43,9\%), ont été examinés et des données sur le suivi étaient disponibles en moyenne pour une période couvrant 7,8 ans. Dans ce groupe, quatre hommes ont présenté une ostéonécrose. Aucune femme n'a été affectée. Tous les patients ont présenté des signes d'ostéonécrose touchant le col du fémur à la radiographie, à l'imagerie par résonance magnétique et à l'examen anatomopathologique, alors que d'autres souffraient en outre de nécrose avasculaire affectant les têtes humérales. L'âge des patients variait de 19 à 36 ans au moment du diagnostic de maladie de Crohn et ils étaient tous de race blanche. Chez un patient, la maladie était confinée au côlon, alors que

voir page suivante

Department of Medicine (Gastroenterology), University of British Columbia, Vancouver, British Columbia

Correspondence and reprints: Dr Hugh Freeman, Gastroenterology, ACU F-137, University of British Columbia Hospital,

2211 Wesbrook Mall, Vancouver, British Columbia V6T 1W5. Telephone 604-822-7216, fax 604-822-7236

Received for publication February 8, 1999. Accepted May 12, 1999 
les trois autres souffraient d'une atteinte de l'iléon terminal et du côlon. L'évolution de la maladie a été jugée pénétrante en raison d'abcès ischio-rectaux concomitants et un patient a présenté un cancer du côlon métastatique. La spondylite ankylosante était présente chez deux patients, mais aucune autre manifestation extra-intestinale n'a été signalée. Deux patients ont reçu des corticostérö̈des de même qu'une nutrition parentérale durant leur maladie. Deux patients n'ont reçu ni corticostéroïdes, ni nutrition parentérale. Parmi les 877 patients atteints de maladie de Crohn, 484 (55,1\%) ont reçu des corticostéroïdes durant leur maladie; cent quatre-vingt-seize $(2,4 \%)$ ont reçu au moins un traitement de nutrition parentérale et $125(14,3 \%)$ ont reçu des corticostéroïdes et une nutrition parentérale. En tout, 311 patients
$(35,5 \%)$ ont subi au moins une résection du grêle. Le taux global de nécrose avasculaire dans la maladie de Crohn a été inférieur à 0,5\%, mais pour les hommes atteints de maladie de Crohn, i l a été d'environ $1 \%$. Dans cette série, le risque de nécrose n'a pu être attribué à l'emploi des corticostéroïdes, de la nutrition parentérale ou des deux formes de traitement combinées. La résection du grêle avec ablation de sa zone absorptive ne s'est pas révélée être un facteur de risque d'ostéonécrose. La nécrose avasculaire (ou ostéonécrose) est une complication osseuse extra-intestinale extrêmement rare qui accompagne parfois la maladie de Crohn, indépendamment des facteurs de risque signalés antérieurement, y compris la corticothérapie ou la nutrition parentérale avec émulsions grasses.
$\mathrm{O}$ steonecrosis, or nontraumatic (aseptic, avascular) bone necrosis, is estimated to account for over $10 \%$ of joint replacements (1). Several clinical disorders have been associated with osteonecrosis, as previously reviewed (2). Osteonecrosis has also rarely been reported in patients with inflammatory bowel disease, particularly Crohn's disease (3-10). In some of these patients, treatment measures used for inflammatory bowel disease have been implicated in the pathogenesis of osteonecrosis, including corticosteroids, parenteral nutrition with lipid emulsions or both. In some patients, other causes of osteonecrosis may be important, such as trauma or chronic alcoholism (1).

Most patients with inflammatory bowel disease and osteonecrosis have been described only in case reports so that the overall rate of this disorder, specifically in patients with Crohn's disease, has not been well established in larger patient series. Only two reports in the literature have attempted to address this issue $(5,11)$. In 1989, Vakil and Sparberg (5) tabulated their clinical experience with osteonecrosis in a group of 204 consecutive patients referred with inflammatory bowel disease at a university teaching hospital during a 10-year period (1977 to 1987). In their reported group, 161 patients received corticosteroids (79\%), and seven $(4.3 \%)$ of these corticosteroid-treated patients developed osteonecrosis; only two patients actually had Crohn's disease. In a report by Bello et al (12), data from 55 patients with Crohn's disease treated with maintenance alternateday prednisone, average dose $25 \mathrm{mg}$ daily, for a mean duration of 6.6 years, revealed no observed instances of osteonecrosis. Neither of these studies used modern imaging methods such as magnetic resonance imaging (MRI) for diagnosis, and postoperative pathological studies on bone specimens confirming osteonecrosis were not reported.

The present report evaluates the clinical experience of osteonecrosis in 877 patients with Crohn's disease consecutively evaluated during a 20-year clinical referral practice experience at a university teaching hospital. The results of the present study indicate that osteonecrosis is a bone disorder of unknown etiology very rarely seen in patients with Crohn's disease. In this series of patients with Crohn's disease, it was not possible to relate directly or even indirectly several previously hypothesized potential risk factors, such as corticosteroids or parenteral nutrition therapies, as well as intestinal resection, to this complication of osteonecrosis.

\section{METHODS AND CASE PRESENTATIONS}

Clinical records of 877 patients with Crohn's disease were retrospectively reviewed by the authors. Four patients with osteonecrosis were found, including two who were previously reported elsewhere (8). Follow-up data were available, with a mean for the entire patient group of 7.8 years. Osteonecrosis was diagnosed on the basis of routine radiographic studies and nuclear scanning, as well as modern imaging methods, including MRI, which has been available at the University of British Columbia Hospital, Vancouver, British Columbia since 1981. Statistical evaluation of the steroid and nonsteroid population included the Fisher's exact test.

Case 1: A 28-year-old man was admitted to a community hospital in January 1987 because of abdominal pain and chronic diarrhea for three months with an associated weight loss of $10 \mathrm{~kg}$. Barium radiographic and colonoscopic examinations revealed ulcerative and stenotic changes of Crohn's disease involving the ileum, descending colon and sigmoid colon. Biopsies showed giant cell granulomas. Fecal cultures and examinations for parasites were negative. Treatment initially comprised intravenous hydrocortisone $480 \mathrm{mg}$ daily and parenteral nutrition (including lipid emulsion). His diarrhea resolved completely, and his treatment was changed after three weeks of intravenous corticosteroids to prednisone $60 \mathrm{mg}$ orally daily. Arthralgias developed in both knees, but radiological studies were normal so he was discharged on 5-aminosalicylic acid (Asacol, Proctor \& Gamble Pharmaceuticals Canada, Inc, Toronto, Ontario) and prednisone $45 \mathrm{mg}$ daily. This dose was gradually reduced over the next two months and then discontinued. A colonoscopy showed ileal and cecal aphthous ulcers. He was asymptomatic for two weeks, but diarrhea recurred up to 10 times/day. There were no joint symptoms. The patient self-directed his prednisone treatment beginning at a dose of $50 \mathrm{mg}$ daily with dosage changes depending on the presence or absence of knee arthralgias. He was seen in another hospital by a different gastroenterologist. Results of a sigmoidoscopy were normal. He was advised to reduce his corticosteroid dosage but used 
$10 \mathrm{mg}$ to $20 \mathrm{mg}$ daily over the next year. In August 1988, he ceased using prednisone, but right shoulder pain developed after a fall at his workplace and radiographs showed features of right humeral head osteonecrosis.

In August 1988, he was first seen at the University of British Columbia Hospital. His only symptom was right knee pain. Radiographs, bone scan and MRI showed osteonecrosis in the right humeral head and changes of osteonecrosis in both femoral condyles. In addition, MRI revealed early changes in both femoral heads. In November 1988, arthroscopy and decompression drilling of the left lateral femoral condyle were done to reduce pain and improve vascularization. Clinical evaluation in July 1989 revealed resolution of knee pain. No further follow-up data were available.

Case 2: A 29-year-old man first developed diarrhea, up to 10 watery movements daily, in 1983. Colonoscopic evaluation in a community hospital showed colitis with deep ulcerations, thought to be consistent with Crohn's colitis. He was treated with sulphasalazine $2 \mathrm{~g}$ daily and corticosteroid enemas. His symptoms improved, but he had occasional episodes of bloody diarrhea. In 1986, his bloody diarrhea became more severe, up to 20 times per day. Progressive weight loss, estimated to be about $15 \mathrm{~kg}$, developed. He was admitted to hospital and treated with 5 -aminosalicylic acid $1600 \mathrm{mg}$ (Asacol) and intravenous hydrocortisone $400 \mathrm{mg}$ daily. Colonoscopic changes were extensive with cecal and rectal sparing. Biopsies showed inflammatory changes only, with no granulomas. He was transferred to another hospital for parenteral nutrition (including lipid emulsion). His weight increased by $10 \mathrm{~kg}$, and his diarrhea improved with a frequency of about 10 movements/day. Surgical treatment was declined.

In April 1987, he was referred for further management to the University of British Columbia Hospital. Physical examination showed steroid-related 'Cushingoid' features. His weight was now identical to his documented preillness weight. Laboratory studies were normal, except for a serum albumin level of $32 \mathrm{~g} / \mathrm{L}$ (normal range 35 to $50 \mathrm{~g} / \mathrm{L}$ ). Colonoscopy confirmed previous findings; inflammatory pseudopolyps were also present. Biopsies showed only inflammatory changes; no granuloma was present. Parenteral nutrition was discontinued, and he was discharged from hospital having two nonbloody soft bowel motions daily. His prednisone dose was progressively reduced over the next six weeks to 10 mg daily. By August 1987, results of his laboratory studies, including serum albumin levels, were normal and the prednisone dose was further tapered to $5 \mathrm{mg}$ daily. One week later, he noted discomfort in both hips. Because it was believed that osteonecrosis might be present, the prednisone was terminated.

Results of radiographic studies of his hips in September and October 1987 were normal; no changes were present to suggest osteonecrosis. In November 1987, MRI of both hips showed bilateral subarticular low signal changes on both T1 and $\mathrm{T} 2$ weighted images consistent with osteonecrosis. Over the next three months, there were no intestinal symptoms, but hip pain was present. In March 1988, MRI showed progression of the osteonecrosis, particularly in the right femoral head. In February 1989, he complained of pain in both shoulders, and radiographic studies demonstrated osteonecrosis, particularly in the right humeral head. In December 1990, he presented emergently to another teaching hospital with an acute abdomen. Laparotomy revealed a perforated rectosigmoid carcinoma with generalized peritonitis. Extensive bilateral bronchopneumonia developed in the postoperative period followed by death.

Case 3: A 36-year-old man presented with an ischiorectal abscess that required incision and drainage in 1989. Because of diarrhea and a weight loss of $20 \mathrm{~kg}$, further investigations were done. Fecal cultures and studies for parasites were negative. Colonoscopy showed superficial and deep serpentine ulcers, mucosal swelling, erythema, friability and pseudopolyps in the transverse and descending colon, with a normal ascending colon and rectum. The ileum was erythematous but not ulcerated. Multiple ileal and colonic mucosal biopsies showed severe but patchy inflammatory changes, but no granulomas. Upper gastrointestinal endoscopy and biopsies revealed focal gastritis (without Helicobacter species) and nonspecific duodenitis; no granulomas were found. Barium radiographs of the upper gastrointestinal tract were normal, but a barium enema showed changes of Crohn's disease.

The patient had a four-year history of right hip pain that worsened with walking and was associated with morning stiffness. Slight tenderness of the right hip was noted during his initial evaluation in 1989; his right leg was externally rotated, with a restricted range of motion in both legs, more on the right side. Radiographs of both hips in July 1989 revealed changes typical of avascular necrosis in the left hip and gross destruction of the right hip. In addition, there was radiographic evidence of sacroiliitis and early ankylosing spondylitis.

Treatment in 1989 consisted of intravenous antibiotics and oral 5-aminosalicylic acid with symptomatic improvement. The patient was not treated with corticosteroids at that time or later because it was believed that they might result in worsening of the osteonecrosis. He did not seek further medical care until August 1991, when perianal pain and sepsis recurred. The patient declined to undergo further barium or endoscopic gastrointestinal studies. Incision and drainage of an abscess, and intravenous antibiotic therapy led to resolution of his perianal disease. Later hip radiographs and MRI, obtained in 1991, showed worsening osteonecrosis with destruction of both hips. Hip replacement surgery was declined.

Case 4: A 10-year-old boy was initially hospitalized in 1971 and then in 1981 for polyarthritis involving his knees, ankles and wrists. Treatment with acetylsalicylic acid both times resulted in symptomatic improvement. In 1981, radiographs of the pelvis, hips, hands and feet were normal except for poor definition of the sacroiliac joint margins. A radionuclide bone scan showed increased uptake in both sacroiliac joints. Because of some diarrhea, barium radiographs of the upper and lower gastrointestinal tracts were obtained, and showed 
TABLE 1 Characteristics of Crohn's disease in osteonecrosis patients
treated at the University of British Columbia Hospital,
Vancouver, British Columbia

\begin{tabular}{lcccc}
\hline Age*/sex $^{*}$ & Site & Behaviour $^{+}$ & $\begin{array}{c}\text { Extraintestinal } \\
\text { features }\end{array}$ & Other \\
\hline 28/male & Ileocolon & $\begin{array}{c}\text { Nonstricturing and } \\
\text { nonpenetrating } \\
\text { 29/male }\end{array}$ & $\begin{array}{c}\text { Peripheral } \\
\text { arthropathy }\end{array}$ & \\
Colon & Penetrating & None & $\begin{array}{c}\text { Colorectal } \\
\text { cancer }\end{array}$ \\
19/male & lleocolon & Penetrating & $\begin{array}{c}\text { Spondylo- } \\
\text { arthropathy and } \\
\text { peripheral } \\
\text { arthropathy } \\
\text { Spondylo- }\end{array}$ & \\
\hline & Ileocolon & $\begin{array}{c}\text { Nonstricturing } \\
\text { and nonpenetrating } \\
\text { arthropathy }\end{array}$ & \\
\hline
\end{tabular}

*Age at diagnosis of Crohn's disease; ${ }^{+}$Clinical behaviour classified as nonstricturing and nompenetrating, or stricturing and penetrating

changes characteristic of Crohn's disease involving the distal ileum and transverse colon. Since 1981, he was treated with sulphasalazine $4 \mathrm{~g}$ daily and supplements of iron and folic acid.

In September 1985, abdominal pain and diarrhea developed. Examination revealed right lower quadrant tenderness. An anal fistula was present. Sigmoidoscopy showed multiple discrete aphthous ulcers; a rectal biopsy showed active inflammation but no granulomas. Laboratory studies were normal, except for an erythrocyte sedimentation rate of $82 \mathrm{~mm} / \mathrm{h}$; tests for rheumatoid factor and antinuclear antibodies were negative. Human leukocyte antigen typing was negative for human leukocyte antigen-B27. Blood and fecal cultures, including cultures for Yersinia species, and studies for parasites were negative. Abdominal ultrasound revealed no abscess. Barium radiographic studies showed changes in the distal ileum and transverse colon similar to those recorded in 1981, as well as narrowing of the distal descending colon. The sacroiliac joint margins were poorly defined, and there was irregular demineralization of the right and left femoral heads. Some hip pain was present, particularly on the right side. Because of the patient's gastrointestinal symptoms, he was treated with a low residue diet and metronidazole $750 \mathrm{mg}$ daily orally. Because of worsening hip pain and decreasing mobility, he underwent total replacement of the right hip in 1986 and of the left hip in 1988. The synovium of each hip joint showed villous hyperplasia with synoviocyte hypertrophy as well as hyperplasia, fibrosis and inflammation of the subsynovium. Sections from the femoral head showed extensive degeneration of articular cartilage with osteonecrosis of the bony trebeculae; however, no wedgeshaped sclerosis or cystic degeneration of the subchondral region was evident. Granulomas were not present in synovium, joint capsule, skeletal muscle or bone.

\section{RESULTS}

Osteonecrosis rates: The records of 877 patients with Crohn's disease seen during a 20-year period were retrospectively analyzed to determine the frequency of osteonecrosis
TABLE 2

Characteristics of osteonecrosis patients with Crohn's disease treated at the University of British Columbia Hospital, Vancouver, British Columbia

\begin{tabular}{|c|c|c|c|c|c|}
\hline Age*/sex & Age Dx & $\begin{array}{c}\text { Bones } \\
\text { involved }\end{array}$ & Steroids & TPN & SB resection \\
\hline 28/male & 29 & $\begin{array}{c}1 \mathrm{H}, 2 \mathrm{FC} \\
2 \mathrm{FH}\end{array}$ & Yes & Yes & No \\
\hline 29/male & 33 & $2 \mathrm{H}, 2 \mathrm{FH}$ & Yes & Yes & No \\
\hline 36/male & 36 & $2 \mathrm{FH}$ & No & No & No \\
\hline 19/male & 23 & $2 \mathrm{FH}$ & No & No & No \\
\hline
\end{tabular}

*Age at diagnosis of Crohn's disease. Age Dx Age at diagnosis of Crohn's disease; FC Femoral condyle; FH Femoral head; H Humerus; SB Small bowel; TPN Total parenteral nutrition

and possible factors that might have influenced its development. This represented the entire clinical experience of a sole gastroenterologist in a tertiary care university teaching hospital (11). Of these 877 patients, 492 (56.1\%) were female and 385 (43.9\%) were male. Therefore, the overall osteonecrosis rate in this series of Crohn's disease patients was four in 877 (approximately 0.5\%). All patients with osteonecrosis were male, so the actual rate of osteonecrosis in men was four in 385 (about 1\%). No women were detected with osteonecrosis.

Characteristics of Crohn's disease: Table 1 shows the clinical characteristics of the four male patients with osteonecrosis detected in this group of 877 patients with Crohn's disease. All patients had a diagnosis of Crohn's disease established before age 40 years. All patients had at least colonic involvement, and three also had ileal inflammatory changes. The clinical behaviour of the Crohn's disease was classified as penetrating in two, but no patient had stricturing or stenosing disease. Of these four patients, three had a central spondyloarthropathy, a peripheral arthropathy or both. Other extraintestinal features associated with Crohn's disease were not observed. One patient died with a metastatic colorectal cancer. Follow-up data were available on all 877 patients with a mean of 7.8 years.

Characteristics of osteonecrosis: Table 2 shows characteristics of the osteonecrosis. Three of the four patients developed osteonecrosis after the diagnosis of Crohn's disease was established; two of these three patients received corticosteroids and parenteral nutrition, while one patient did not receive either form of therapy. In one patient, the diagnosis of osteonecrosis was established concomitant with the diagnosis of Crohn's disease; this patient did not receive corticosteroids or parenteral nutrition. All patients had bilateral osteonecrosis detected in the femoral heads. Two patients also had changes of osteonecrosis detected in the other sites, in particular, the humerus; both patients received corticosteroids and parenteral nutrition. One patient also had a recent history of a work-related traumatic injury to his shoulder. None of the four patients was an alcohol abuser or provided evidence of alcohol use, even indirect, such as altered liver chemistry tests. Two patients received orthopedic 


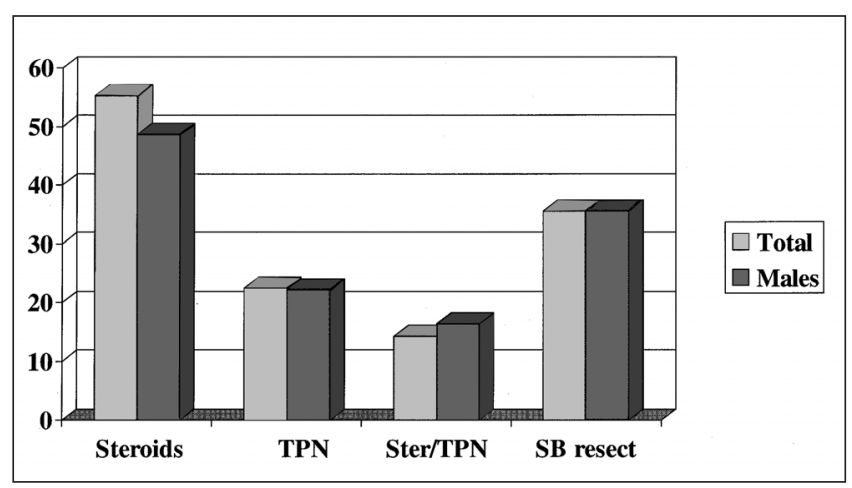

Figure 1) Percentage of total patients (and males) with Crohn's disease treated with corticosteroids (steroids), parenteral nutrition (TPN), both forms of therapy (ster/TPN) or small bowel resection (SB resect) in 877 cases

surgical treatment for their osteonecrosis. One patient had hip replacement surgery, and one patient had decompressive drilling. Two patients refused surgical treatment. Follow-up periods for the two osteonecrosis patients treated with steroids were 22 months and 59 months, respectively, for a mean of 3.3 years, while follow-up periods for the two patients not treated with steroids were 24 months and 80 months, respectively, for a mean of 4.3 years.

Potential risk factors for osteonecrosis: Several possible risk factors for osteonecrosis were independently evaluated. These are schematically shown in Figure 1. Risk factors included use of corticosteroids, use of parenteral nutrition (all administered solutions included lipid emulsions), or concomitant corticosteroid and parenteral nutrition. In addition, because nutrient absorption may be a factor in the pathogenesis of bone disease in Crohn's disease, the frequency of small bowel resection in this group of 877 patients was also considered.

A total of 483 patients with Crohn's disease (55.1\%) were treated with some form of corticosteroid during their management, usually oral prednisone, for at least one treatment course, most often as part of their pharmacological management. For men with Crohn's disease, 187 of 385 (48.6\%) received at least one course of corticosteroids. For prednisone, the usual initial dose given was 20 to $40 \mathrm{mg}$ daily, and this dose was tapered over a period of four to 10 weeks. Occasionally, patients required longer periods of lower doses of 5 to $10 \mathrm{mg}$ daily before the oral prednisone could be discontinued. Hospitalized patients treated with intravenous corticosteroids usually received hydrocortisone $200 \mathrm{mg}$ daily (equivalent to about $40 \mathrm{mg}$ of prednisone).

This was usually tapered in the hospital to approximately $100 \mathrm{mg}$ daily before conversion to an oral corticosteroid. Fewer than $1 \%$ of all corticosteroid-treated patients received budesonide as a form of corticosteroid therapy during their treatment.

A total of 196 patients (22.4\%) received parenteral nutrition during hospitalization, either for primary therapy to provide therapeutic 'bowel rest', sometimes with other forms of pharmacological management, including corticosteroids, or for direct nutritional support, usually in the perioperative period. Of these 196 patients who received parenteral nutrition, 125 also received corticosteroids at some time during their disease course, often concomitantly with this nutritional support therapy. Of the 385 men, 85 received a course of parenteral nutrition and 63 received both corticosteroids and parenteral nutrition.

A total of 311 patients (35.5\%) required hospitalization for one or more small intestinal resections for their Crohn's disease, usually because of obstructing symptoms. No patient who had a small bowel resection developed osteonecrosis. Of the 385 men, 137 (35.5\%) had a small bowel resection.

\section{DISCUSSION}

This investigation evaluated the detection rate of osteonecrosis in a large series of consecutively evaluated patients with inflammatory bowel disease, specifically Crohn's disease. Of the 877 patients seen by a single clinician over 20 years in a referral-based tertiary care university teaching hospital setting, osteonecrosis was detected in four patients for an overall rate of approximately $0.5 \%$. Because all four patients were male, the actual rate for men in this study was about $1 \%$. No case was detected in women. These results are similar to those of previous studies $(5,12)$. In one study (5), seven of 204 consecutively evaluated patients from a similar tertiary care setting developed osteonecrosis; of these, however, only two had Crohn's disease and, as in the present report, both were male. There were also some differences. For example, it was not clear in that study whether patients with inflammatory bowel disease also had already defined osteonecrosis at the time of their initial referral, as in the present study for one patient (case 1). In addition, diagnosis was entirely dependent on the use of radiographs and, rarely, nuclear scanning, which is quite different from the experience in the present study; in our hospital, MRI has been available from 1981 for the detection of early changes of osteonecrosis (13). In a later retrospective study of 55 patients treated with alternate-day prednisone (average dose prednisone $25 \mathrm{mg}$ every other morning) for a mean duration of 6.6 years, no observed instance of osteonecrosis was recorded. In that study, men predominated (37 patients [67.3\%]), and 24 patients $(43.6 \%)$ also had a prior intestinal resection (12). Thus, the present study, based on a series of consecutively evaluated patients in a tertiary care referral setting, confirms that this debilitating extraintestinal osseous complication of osteonecrosis is extremely rare in patients with Crohn's disease.

The cause of osteonecrosis in Crohn's disease is not known. Corticosteroids have been implicated in the past because of a relationship apparently established for some other clinical disorders, including renal transplant recipients $(14,15)$ and systemic lupus erythematosis patients (16-19). A firm causal relationship has not been established for most disorders, including Crohn's disease. Case reports detailing this specific complication in Crohn's disease have failed to demonstrate a consistent association. Indeed, if anything, the relationship detailed in these anecdotal experiences has been quite contradictory (2). No definitive dose-response re- 
lationship has been described in Crohn's disease, similar to recent prospective observations in patients with either inflammatory arthritis or asthma treated with corticosteroids (20). Moreover, no consistent temporal relationship for the development of osteonecrosis has been described in patients with Crohn's disease (2). Finally, no definite biological explanation has been provided (2) to explain the role, if any, of corticosteroids in those very rare patients with osteonecrosis and Crohn's disease. Similar considerations related to parenteral nutrition, or the combined use of corticosteroids and parenteral nutrition, have failed to define any evidence for a cause-effect relationship. In the present experience, two patients who were treated with corticosteroids and parenteral nutrition developed osteonecrosis. However, in this same

\section{REFERENCES}

1. Mankin HJ. Nontraumatic necrosis of bone (osteonecrosis). N Engl J Med 1992;326:1473-9.

2. Freeman HJ. Osteomyelitis and osteonecrosis in inflammatory bowel disease. Can J Gastroenterol 1997;11:601-6.

3. Brom B, Bank S, Marks IN, Cobb JJ. Periostitis, aseptic necrosis, and arthritis occurring in a patient with Crohn's disease. Gastroenterology 1971;60:1106-9.

4. Shapiro SC, Rothskin FC, Newman AJ, Fletcher B, Halpin TC Jr. Multifocal osteonecrosis in adolescents with Crohn's disease: a complication of therapy? J Pediatr Gastroenterol Nutr 1985;4:502-6.

5. Vakil N, Sparberg M. Steroid-related osteonecrosis in inflammatory bowel disease. Gastroenterology 1989;96:62-7.

6. Culp PW, Schaffer JL, Osterman AL, Bora FW. Kienbock's disease in a patient with Crohn's enteritis treated with corticosteroids. J Hand Surg 1989;14:294-6.

7. Ruttenberg D, Burns D, Learmonth I, Heselson N. Steroid-related avascular necrosis and Crohn's disease. S Afr Med J 1990;77:426.

8. Freeman HJ, Kwan WCP. Non-corticosteroid-associated osteonecrosis of the femoral heads in two patients with inflammatory bowel disease. N Engl J Med 1993;329:1314-6.

9. Malcorps J, Eekhaut M, Dierckxsens P. Bilateral stage III osteonecrosis of the femoral head treated with core decompression. Case report and review of the literature. Acta Orthop Belg 1996;62:241-3.

10. Arnold CA, Tavares JO. Long-term follow-up of bilateral steroid-induced osteonecrosis of the lateral femoral condyles in a patient with Crohn's disease. Am J Knee Surg 1998;11:236-40.

11. Freeman HJ. Application of the Vienna classification for Crohn's experience, two patients with Crohn's disease who were not treated with corticosteroids or parenteral nutrition also developed osteonecrosis. Finally, in this study, analyses of the frequency of use of corticosteroids, parenteral nutrition or both modalities, as well as the requirement for small intestinal resection, provided no evidence for their potential role in predisposing patients to osteonecrosis.

\section{CONCLUSIONS}

In this series of 877 consecutively evaluated patients with Crohn's disease, osteonecrosis was rarely encountered. Despite the frequent requirement in this patient population for corticosteroid therapy, parenteral nutrition or both, identical numbers of patients developed osteonecrosis.

disease to a single clinician database of 877 patients. Can J Gastroenterol. (In press)

12. Bello C, Goldstein F, Thornton JJ. Alternate-day prednisone treatment and treatment maintenance in Crohn's disease. Am J Gastroenterol 1991;86:460-6.

13. Madsen PV, Andersen G. Multifocal osteonecrosis related to steroid treatment in a patient with ulcerative colitis. Gut 1994;35:132-4.

14. Huberman ET, Cristofaro RI. Avascular necrosis of bone as a complication of renal transplantation. Semin Arthritis Rheum 1976;6:189-206.

15. Elmstedt E. Incidence of skeletal complications in renal graft recipients. Effects of changes in pharmacotherapy. Acta Orthop Scand 1982;53:853-6.

16. Zizic TM, Hungerford DS, Stevens MB. Ischemic bone necrosis in systemic lupus erythematosis. The early diagnosis of ischemic necrosis of bone. Medicine (Baltimore) 1980;59:134-42.

17. Bergstein JM, Wiens P, Fish AJ. Avascular necrosis of bone in systemic lupus erythematosis. J Pediatr 1974;85:31-5.

18. Klippel JH, Gerber LH, Pollak L, Decker JL. Avascular necrosis in systemic lupus erythematosis. Am J Med 1979;67:83-7.

19. Smith EF, Sweet DE, Brunner CM. Avascular necrosis in systemic lupus erythematosis. An apparent predilection for young patients. Ann Rheum Dis 1976;35:227-32.

20. Colwell CW Jr, Robinson CA, Stevenson DD, Vint VC, Morris BA. Osteonecrosis of the femoral head in patients with inflammatory arthritis or asthma receiving corticosteroid therapy. Orthopedics 1996;19:941-6. 


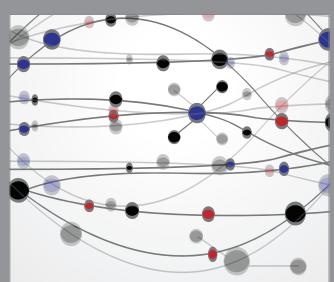

The Scientific World Journal
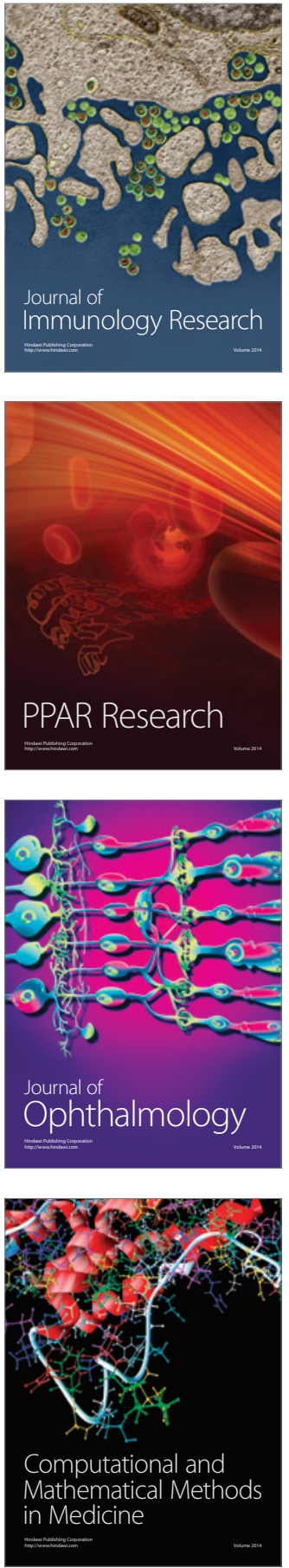

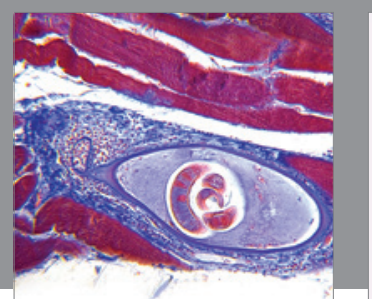

Gastroenterology Research and Practice

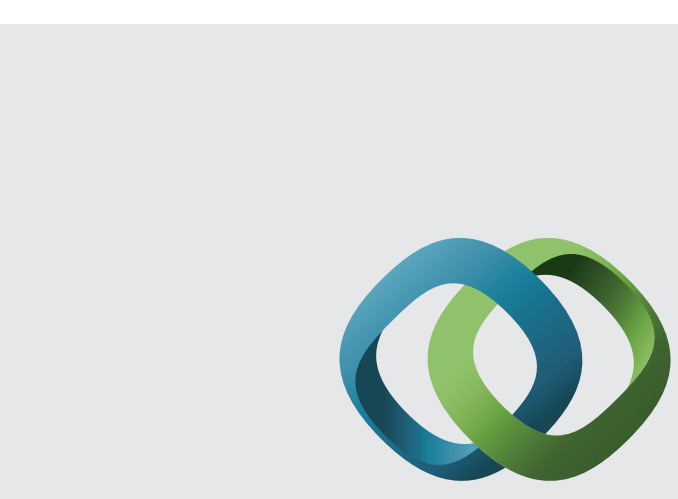

\section{Hindawi}

Submit your manuscripts at

http://www.hindawi.com
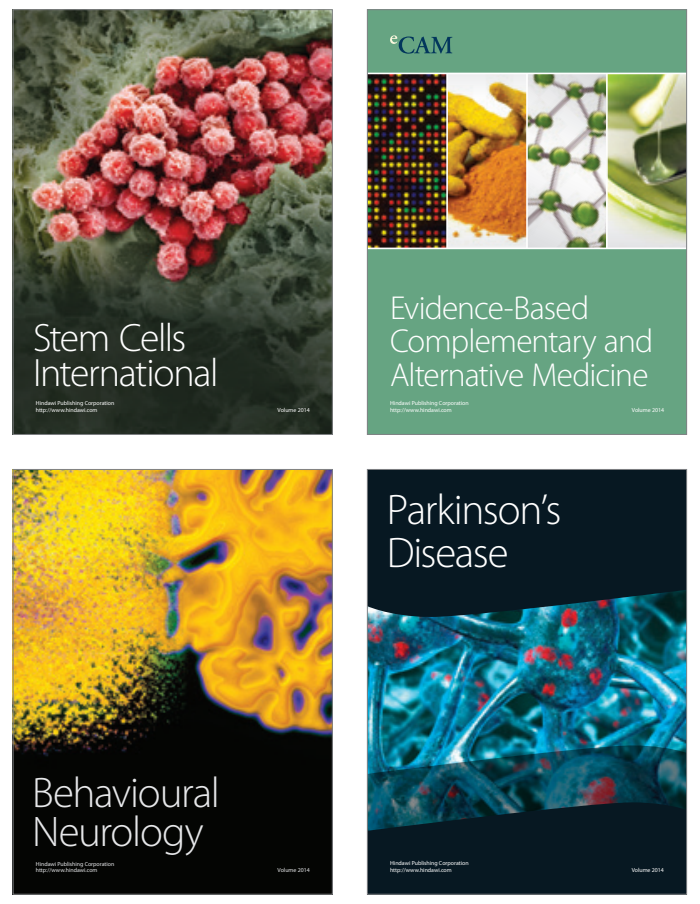
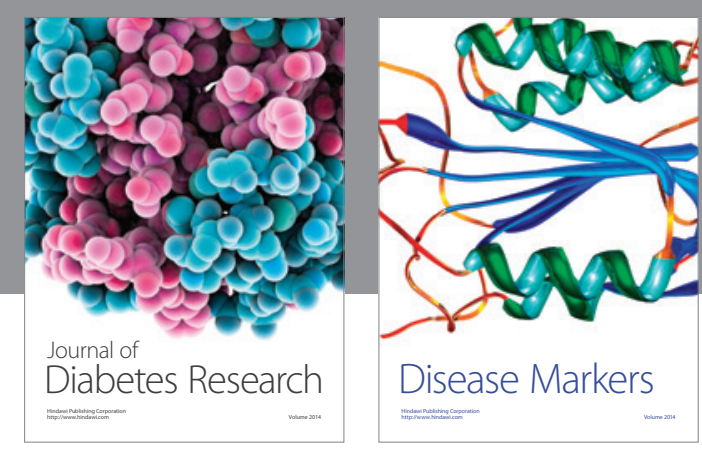

Disease Markers
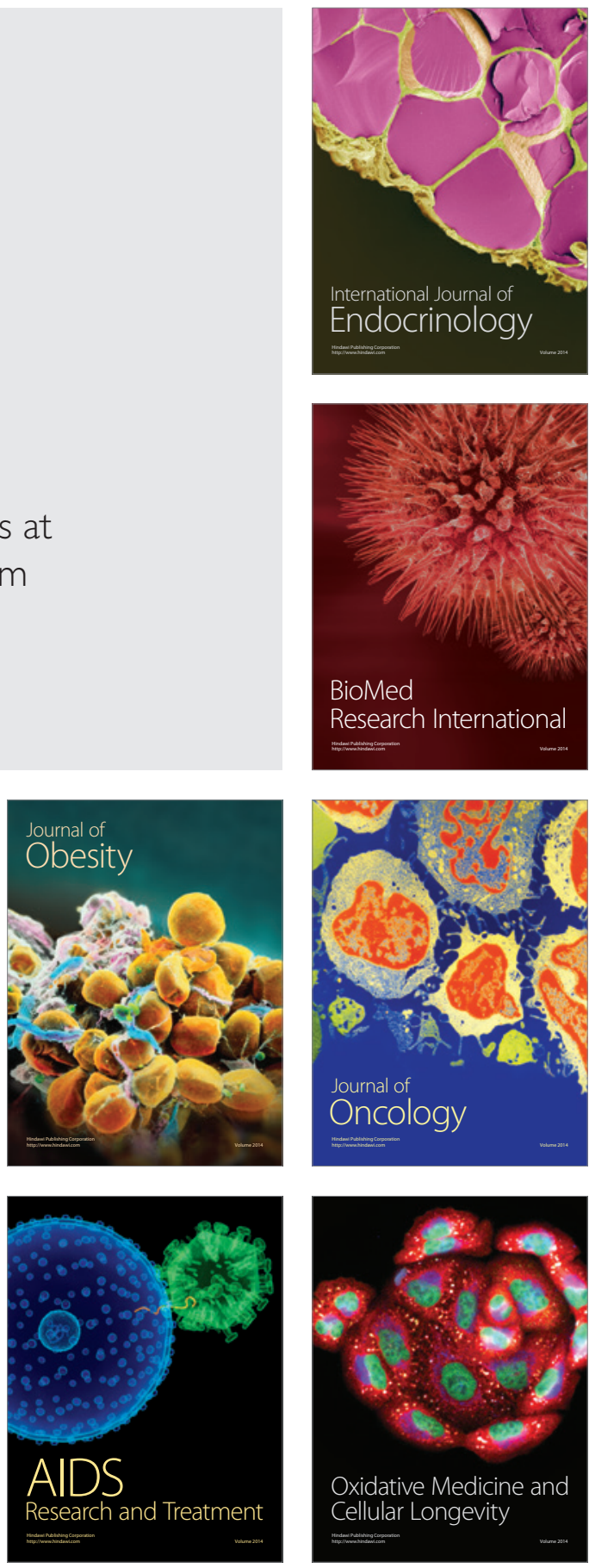